\title{
Effect of $K$ Addition and Acidification of Zeolite Support on the Performance of Zr:Mo/Hzsm-5 Modified Catalyst in Methane Aromatization
}

\author{
Syed Tajammul Hussain ${ }^{*}, 1$ and Ghazala Hasan ${ }^{2}$ \\ ${ }^{I}$ National Centre For Physics, Quaid-i-Azam University Complex, Islamabad, 43520, Pakistan \\ ${ }^{2}$ Chemistry Department, Quaid-i-Azam University, Islamabad, 43520, Pakistan
}

\begin{abstract}
The conversion of methane into higher hydrocarbons and aromatics on potassium doped modified zeolite $\mathrm{Zr}$ :Mo catalysts under non oxidizing conditions have been studied in a fixed bed catalytic reactor system at $450{ }^{\circ} \mathrm{C}$ and at atmospheric pressure. The potassium addition reduces the formation of carbon during the catalytic reaction. This also results in the stability of the catalyst system and increased aromatics production. This is due to electronically modified active sites and increase in Bronsted acidity.
\end{abstract}

Keywords: Zr:Mo modified zeolit catalyst, potassium doping, methane conversion.

\section{INTRODUCTION}

Production of valuable aromatic hydrocarbons like benzene, naphthalene form aromatization of methane has attracted considerable attention of Scientists. Efforts have been devoted to increase efficiency and selectivity of catalyst for aromatization, which is thermodynamically a difficult process, particularly in the absence of oxygen. Oro and Han reported the synthesis of aromatic hydrocarbons from methane over silica gel at $1273 \mathrm{~K}$ [1]. In addition, this reaction has been studied over other catalytic systems such as Ga-Pt/H-Ga-silicates [2], Mo/HZSM-5 and Zn/HZSM-5 catalysts [3], carbonaceous materials [4]. After that, high silica-zeolite supported Pt-Cr catalysts (Lucia et al. 2002), multifunctional multi-metal oxides [5], metal oxide and supported metal catalysts [6]. More recently, the effect of Fe additive on the catalytic activity and coking rate of Mo/HZSM-5 catalyst for methane and ethane aromatization has been reported [7]. Methane activation and conversion over Mo modified acidic zeolite catalyst can proceed without the need of any oxidants. Compared with methane oxidative coupling (MOC) and methane partial oxidation reactions, the advantage of methane non-oxidative transformation process is that the selectivity to higher hydrocarbons is high and the main product benzene is easier to be separated from methane feed. In addition, many problems causing from the side reaction such as methane complete oxidation can be avoided under non oxidative reaction conditions. An increasing number of papers on this research area has been published recently $[8,9]$ in which characterizations of the catalytic and physical properties of the catalysts have been reported.

In order to obtain a highly active and stable catalyst with less carbon deposition during the catalytic reaction, the effect of dopant conditions, concentration of acid sites within the system still is the main interest in this article. This work

*Address correspondence to this author at the National Centre For Physics, Quaid-i-Azam University Complex, Islamabad, 43520, Pakistan; Tel: +0092-51-2077308; Fax: +00-92-51-2077395; E-mail: dr_tajammul@yanoo.ca reports a study in which increase in Bronsted acid sites of the ZSM 5 catalyst support and addition of $\mathrm{K}$ as a dopant produces very interesting results during the aromatization of $\mathrm{CH}_{4}$.

\section{EXPERIMENTAL}

Commercially available ZSM-5 zeolite was treated with $1 \mathrm{~N}$ ammonium nitrate solution at around $368 \mathrm{~K}$ for one hour. The process was repeated thrice and then the final slurry was dried at 373K for four hours. Modified ZSM-5 was used as a catalyst support. $5 \% \mathrm{Zr}: 10 \% \mathrm{Mo}: 1 \% \mathrm{~K}$, balance ZSM-5 modified supported catalyst was prepared by using the procedure described elsewhere [6]. Two samples were prepared one with " $K$ " as a dopant and the other without " $K$ " dopant. Both catalyst samples were dried at $373 \mathrm{~K}$ and then calcined at $873 \mathrm{~K}$ for 6 -hours.

\section{Catalytic Characterization}

The structure and surface acidity of the catalysts were studied using $\mathrm{NH}_{3} \mathrm{TPD}$. This experiment was carried out in an automatic analyzer apparatus (AMI Company, USA) equipped with a thermal conductivity detector (TCD). The test was arried out with $0.3 \mathrm{~g}$ sample placed in a quartz tube (6mm id). It was flushed with $\mathrm{He}$ gas at $773 \mathrm{~K}$ for $2 \mathrm{~h}$. Then cooled down to $318 \mathrm{~K}$ and ammonia was adsorbed until saturation, then it was flushed with He till the TCD baseline was kept stable. The sample was heated to $873 \mathrm{~K}$ at a rate of $10 \mathrm{~K} / \mathrm{min}$, at the same time the $\mathrm{NH}_{3}$ desorption curve was recorded. Similarly CO-chemisorption was performed with Micromertics ASAP-2000 equipment on the samples. 0.5 gms of catalyst was loaded inside u-shaped catalytic reactor, flushed with argon to remove air and following the procedure describe above CO-pulse size $0.5 \mathrm{mls}$ was injected over the catalyst bed, the adsorption of $\mathrm{CO}$ was monitored by on line TCD detector and when the saturation was achieved, the reaction stopped. The \% Dispersion of active metals on the surface was calculated, assuming one mole of $\mathrm{CO}$ adsorbed on one mole of Mo and $\mathrm{Zr}$ [6]. 


\section{Catalytic Studies}

Catalytic tests on both the samples were carried out in a fixed bed catalytic reactor system (Fig. 1). $0.5 \mathrm{~g}$ of the catalyst was placed inside the quartz reactor tube, the catalyst was held with quartz wool on both sides. The catalyst sample was treated with argon to remove air trapped inside the system, then it is reduced at $723 \mathrm{~K}$ with hydrogen for 4-hours. Argon was passed again at same temperature for 30 minutes. The stream was switched to methane and the reactor was brought to $973 \mathrm{~K}$ for the catalytic reaction. The catalytic test was performed at atmospheric pressure and a methane space velocity of $1400 \mathrm{mlg}^{-1} \mathrm{~h}^{-1}$. The products were analyzed with on line GC fitted with poropak Q column and flame ionization detectors Conversion and selectivity were calculated on the carbon number basis.

\section{RESULTS AND DISCUSSIONS}

Specific surface area and metals dispersion were determined by BET and CO-chemisorption. The amount of carbon deposited on the catalyst during catalytic run on both samples was determined by CHNS (Carbon Hydrogen, Nitrogen and Sulfur analyzer) analyzer Balzer Inc, Switzerland and CO-chemisorption (10\% CO, 90\% Helium) was used to calculate the $\%$ dispersion of active sites on the surface and reported in Table $\mathbf{1 .}$

Table 1. Pore Volume, BET Surface Area and COChemisorption

\begin{tabular}{|c|c|c|c|}
\hline Catalyst & $\begin{array}{c}\text { BET } \\
\mathbf{m}^{2} \mathbf{g}^{-1}\end{array}$ & $\begin{array}{c}\text { Pore Volume } \\
\text { mls/g }\end{array}$ & $\begin{array}{c}\text { \% } \\
\text { Disp }\end{array}$ \\
\hline \hline Zr:Mo/M-ZSM-5A & 137 & 1.23 & 27 \\
\hline Zr:Mo:K/M-ZSM-5A & 152 & 2.10 & 37 \\
\hline
\end{tabular}

From Fig. (2) it can be seen that three peaks of $\mathrm{NH}_{3}$-TPD curves correspond to the weak (at $225-240{ }^{\circ} \mathrm{C}$ ), moderately strong ( at $320-330{ }^{\circ} \mathrm{C}$ ) and strong acid sites (at $460-470{ }^{\circ} \mathrm{C}$ ).
When zeolite was modified, the acidity of zeolite shifted towards strongly acidic sites and the peak becomes smooth and narrow. It causes the peak to shift at higher temperature which corresponds to highly acidic sites.

Introduction of $\mathrm{K}$ into the system caused the peak for moderately acidic site became smooth and curve shape for strong acid site was observed. The study realized that addition of $\mathrm{K}$ results in the change in acid centers distribution in comparison with the catalyst without $\mathrm{K}$ and consequently changed the catalytic performance. The strongly acidic sites appear to be the centre of methane aromatization and the weak acid sites only participate the reaction partly. The change in the strongly acidic sites caused the catalytic performance to vary in the reactions.

The above results implies that the modification of zeolites changed the acid centers distribution and this has an influence on the overall geometry of the system which results in the change in catalytic activity, selectivity and stability. The addition of K (Fig. 2d) forms multimetallic surface sites, it though becomes more catalytically active but its strong adsorption stiochiometery is lost, because potassium addition results in the adsorption of ammonia.

The results of online GCMS analysis of the product stream of both samples is presented in the Fig. (3).

The methane conversion and percentage selectivity were calculated by using following formulation.

\section{Methane Conversion (\%)}

(Amount of Methane Reacted/Amount of Methane Input) x 100

where $\mathrm{CH}_{4(\mathrm{in})}$ is moles of methane introduced in the reactor per unit time (flow) and $\mathrm{CH}_{4(\mathrm{out})}$ is the mole of methane at the reactor output. The changes in the total flow due to hydrogen formation during the reaction were approximately calculated from the hydrogen balance, taking into account that every $1 \mathrm{~mol}$ of $\mathrm{CH}_{4}$ converted 1-5-2.0 mol of hydrogen are produced.

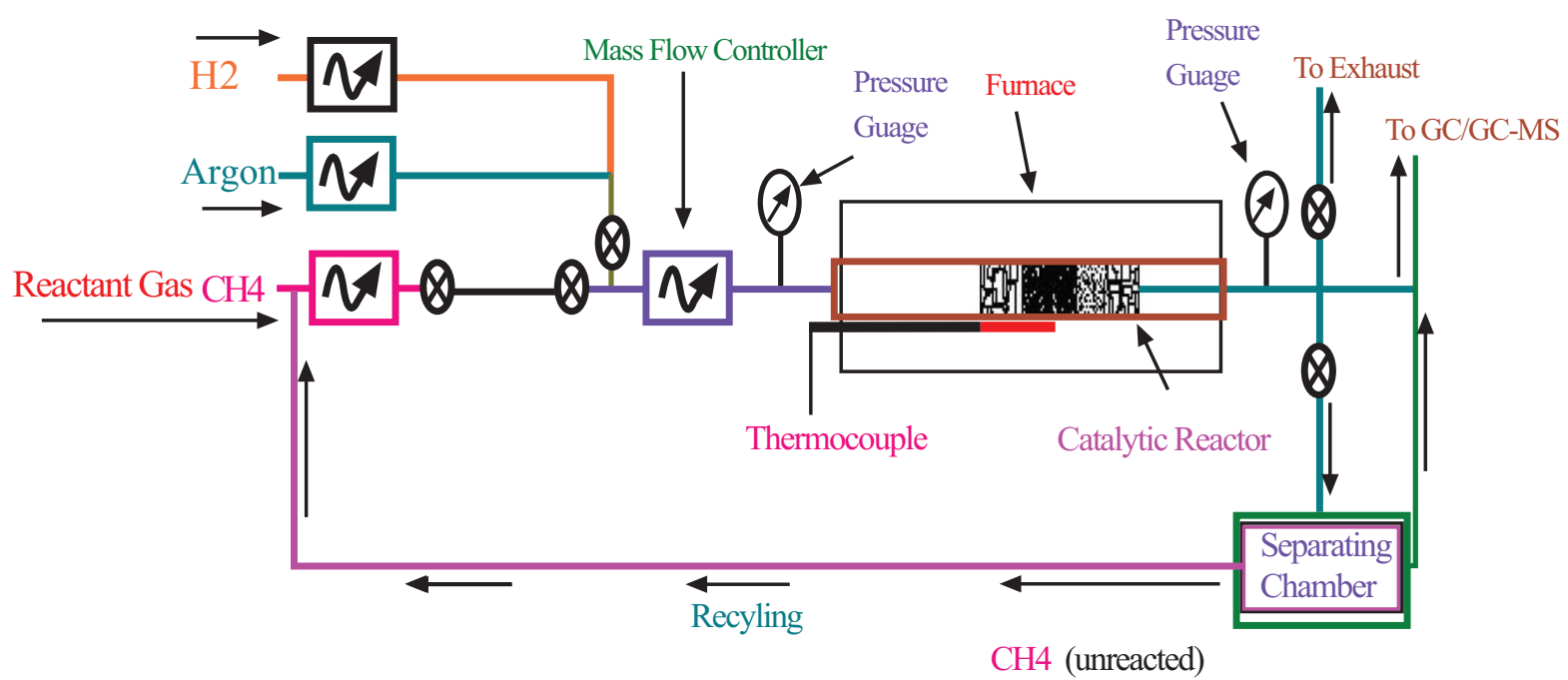

Gas Flow Valve

Fig. (1). Schematic of the catalytic conversion of natural gas. 


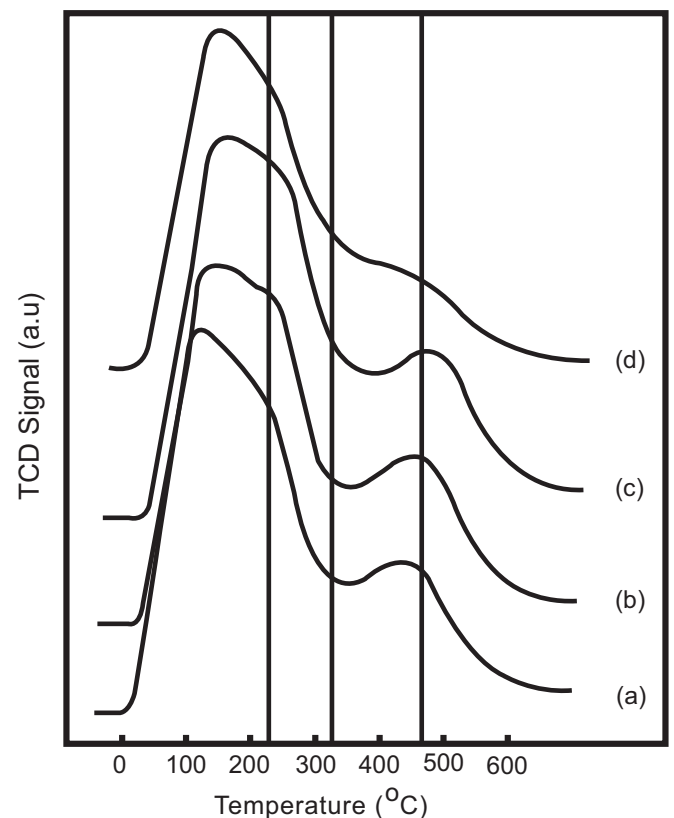

Fig. (2). $\mathrm{NH}_{3}$-TPD Characterization results (a) Zeolite-5, (b) Modified (M) Zeolite-5, (c) Zr:Mo/M-Zeolite-5, (d) Zr:Mo:K/MZeolite-5.

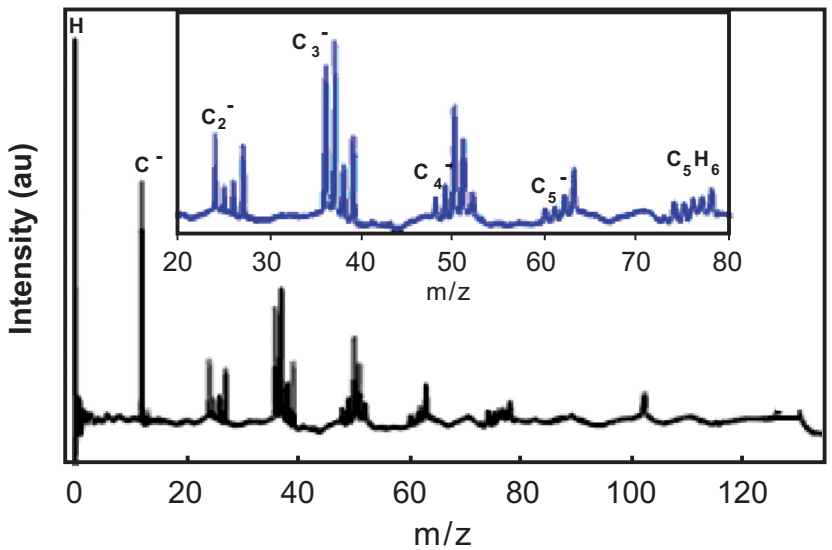

Fig. (3). The MS analysis of the $\mathrm{CH}_{4}$ conversion to different products (Black) without $\mathrm{K}$ (Blue) with $\mathrm{K}$.

Selectivity towards products (\%) was calculated using Carbon of desired product/Carbon of methane reacted $\mathrm{x} 100$ Yield of desired product $(\%)=$ Carbon of desired product/Carbon of Methane Input x 100

Several measurements were made in order to calculate the carbon balance. The total amount of methane converted $\left(\mathrm{CH}_{4}\right.$ conv) and the amount of methane converted into $\mathrm{C}_{2} \mathrm{H}_{2}$ $+\mathrm{C}_{2} \mathrm{H}_{4}$ and $\mathrm{C}_{6} \mathrm{H}_{6}$ were determined by integrating the corresponding MS signals over the duration of the experiment. An approximate estimation for the amount of higher hydrocarbons formed $\left(\mathrm{C}_{\mathrm{x}} \mathrm{H}_{\mathrm{y}}\right)$ was obtained from the chromatograms taken during the experiment. The solid carbon formed during the reaction was determined using CHNS analyzer. Table 2 shows a reasonably good agreement between the methane converted and the total amount of product produced ( $\sum$ - sum of $\mathrm{C}, \mathrm{C}_{2} \mathrm{H}_{2}+\mathrm{C}_{2} \mathrm{H}_{4}, \mathrm{C}_{6} \mathrm{H}_{6}, \mathrm{C}_{\mathrm{x}} \mathrm{H}_{\mathrm{y}}$ ).

Stability test of the catalyst samples were performed to ascertain the role of potassium in maintaining the stability of the K doped catalyst. The results are presented in Fig. (4). The Fig. (4) revealed that potassium addition not only increases the stability of the catalyst in comparison with undoped catalyst, but also creates specific active catalyst centers which help in carbon reduction and increase in product selectivity.

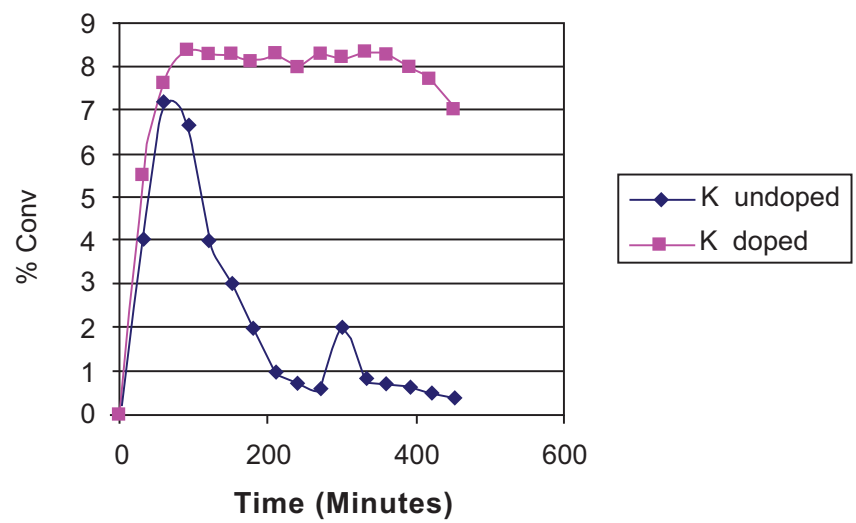

Fig. (4a). Stability tests of the $\mathrm{K}$ doped and undoped catalyst samples.

During the activity and stability tests following observations were made and we propose;

1. The Potassium doped catalyst has the stable activity and selectivity to aromatics. On the catalyst without $\mathrm{K}$ decrease is observed in selectivity to aromatics and an increase in selectivity to $\mathrm{C}_{2}$ hydrocarbons.

2. The ratio of the benzene $/ \mathrm{C}_{\mathrm{x}} \mathrm{H}_{\mathrm{x}}$ hydrocarbons rates (expressed on carbon basis) for Potassium doped sample is twice that observed for non potassium doped samples.

3. The inter-crystalline pore volume of the $\mathrm{K}$ doped sample, is less affected by coke deposition than the undoped sample. More coke is deposited on the surface of undoped sample.

4. Symmetry differences of the $\mathrm{K}$ doped sample we suggest is orthorhombic and monoclinic for undoped sample. This arises from the higher occupancy of zeolite channels by the Potassium.

Table 2. Carbon Balance and Product Selectivity

\begin{tabular}{|c|c|c|c|c|c|c|}
\hline Catalyst & $\begin{array}{c}\mathbf{C H}_{\mathbf{4}} \mathbf{C o n v} \\
\mathbf{( \% )}\end{array}$ & $\begin{array}{c}\mathbf{C} \\
\mathbf{( \% )}\end{array}$ & $\begin{array}{c}\mathbf{C}_{2} \mathbf{H}_{2}+\mathbf{C}_{2} \mathbf{H}_{4} \\
\mathbf{( \% )}\end{array}$ & $\begin{array}{c}\mathbf{C}_{6} \mathbf{H}_{\mathbf{6}} \\
\mathbf{( \% )}\end{array}$ & $\begin{array}{c}\mathbf{C}_{\mathbf{x}} \mathbf{H}_{\mathbf{y}} \\
\mathbf{( \% )}\end{array}$ & $\begin{array}{c}\sum \text { products } \\
\text { Zr:Mo/M-ZSM\% }\end{array}$ \\
\hline \hline Zr:Mo:K/M-ZSM5 & 7.2 & 40 & 20 & 12.0 & 7.3 \\
\hline
\end{tabular}


5. We also suggest that $\beta-\mathrm{MoC} 2$ and $\mathrm{ZrC} 2$ are the carbidic species present on the used undoped sample, whereas both $\mathrm{Mo} 2 \mathrm{C}, \mathrm{ZrC}$ (minor) species are present on the $\mathrm{K}$ doped samples.

This is due to our preparation and starting material. The concentration of Mo and $\mathrm{Zr}$ salts in solution changed with the $\mathrm{pH}$ value as reported in [10]. After mixing with modified zeolite, the $\mathrm{pH}$ of the solution decreased from 6 to 3. By adding ammonia, the $\mathrm{pH}$ of impregnating solution was higher than 9. The high $\mathrm{pH}$ shifted the equilibrium of the reaction towards the formation of $\beta-\mathrm{MoC}_{2}$ and $\mathrm{ZrC}_{2}$ species. Because of high dispersion of our catalyst, we envisage that at high solution $\mathrm{pH}$ adsorption of $\mathrm{Mo}$ and $\mathrm{Zr}$ ions occur not only on the surface of zeolite but also inside the pores of zeolite. These entities migrate on the surface during the catalytic studies and results in the increased Bronsted acid sites. This interpretation is supported by our $\mathrm{NH}_{3}-\mathrm{TPD}$ studies reported in Fig. (2). This is crucial for the formation of active catalyst and also accompanied by the loss of Lewis acid sites [11]. This argument further get support by the increase is surface area of the modified zeolite $\mathrm{K}$ supported samples. Otherwise if there are less $\beta-\mathrm{MoC}_{2}$ and $\mathrm{ZrC}_{2}$ particles on the external surface it could have blocked the pore openings and this would have been resulted in the lesser surface area which is the case on the undoped and non modified catalyst sample. Therefore, we attribute the improvement in activity and product selectivity to an increase in quantity of active sites and specific geometry of the materials due to better $\mathrm{Mo}$ and $\mathrm{Zr}$ dispersion. Observations 4 and 5 mentioned above are consistent and indicate that more coke species are deposited on the undoped K sample.

We consider that the difference of pore structures between $\mathrm{K}$ doped and undoped samples is the most important factor to influence the catalytic performance of the two catalysts. We speculate that $\mathrm{K}$ doped $\mathrm{Zr}: \mathrm{Mo} /$ Modified Zeolite catalyst has two types of active sites: one is two dimensional sinusoidal site and the other the super-cage site. The $\mathrm{K}$ doped catalyst has large pore diameter in comparison with the diameter of HZSM-5, consequently the higher selectivity, is achieved on this sample and less coke deposition. Most of the active sites on the K-doped samples are located near the sinusoidal channels, where as the undoped active centers are located near to super-cage channels, where the formation of carbon and selectivity to products is effected, because the change in adsorption/desorption rate and contact time.

We also propose here, that potassium addition generates higher amount of hydrogen during the methane aromatization and the surface is modified by the electron donor ability of potassium. The formation of coke poison, the catalyst surface and active sites becomes inaccessible and this explains the decrease in catalyst activity and selectivity on the undoped $\mathrm{K}$ sample. We also propose here that potassium addition produces meta-stable phase of Mo and $\mathrm{Zn}$ which is fcc in nature, this phase is reportedly more active, similar argument is proposed by [12]. Our XRD data presented in Fig. (4b) support our proposed nature of Mo and $\mathrm{Zr}$.

The addition of potassium also results in the increase in $\mathrm{pH}$, due to increase $\mathrm{pH}$ the Mo and $\mathrm{Zn}$ species migrate on the external surface of the modified zeolite and interact with the Bronsted acid sites. This is very crucial for the formation of active catalyst. In summary, we attribute the improvement of catalytic activity in case of $\mathrm{K}$ doped catalyst is to an increase in the quantity of acidic active sites due to better Mo:Zn:K dispersion and formation of highly acidic multiple centers.

We suggest here, that the primary reaction path is hydrogen abstraction leading to a formation of $\mathrm{CH}_{3}, \mathrm{CH}_{2}$ and $\mathrm{CH}$ radicals, which react to produce higher hydrocarbons. The process usually leads to a Schulz-Flory distribution [13]. Benzene formation does not follow this distribution and therefore it is highly probable that the actual formation of

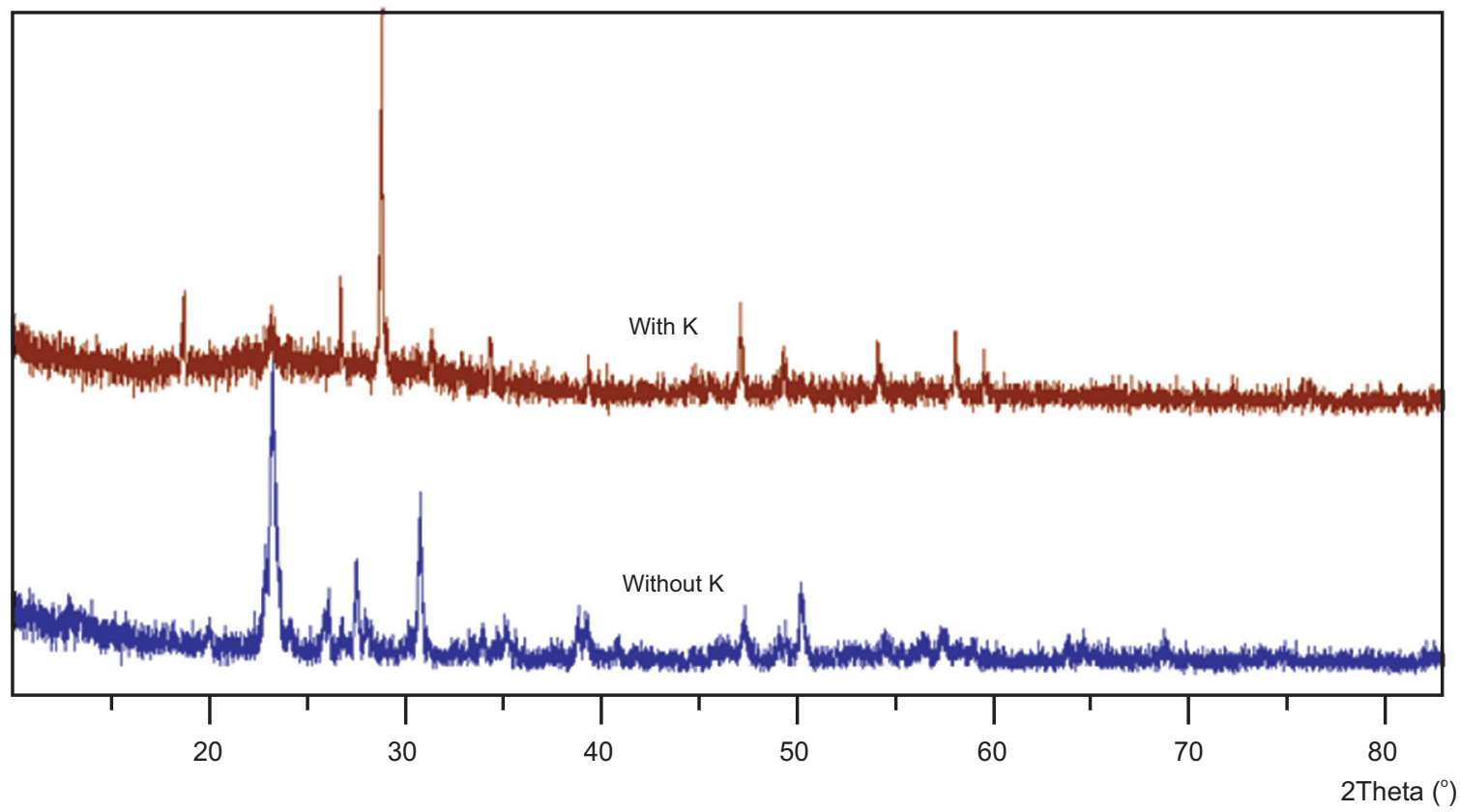

Fig. (4b). XRD study of samples with and without K. 
benzene is a surface process. Such surface process is assumed to take place in methane aromatization over $\mathrm{Zr}: \mathrm{Mo} /$ Zeolite catalyst and addition of $\mathrm{K}$ enhances this ability coupled with modified zeolite. The catalyst is trimetallic: the active centers for hydrogen abstraction from methane were identified as $\mathrm{Mo}_{\mathrm{x}}: \mathrm{Zr}_{\mathrm{x}} \mathrm{C}$, which is formed from $\operatorname{Mo}: \operatorname{Zr}\left(\mathrm{O}_{\mathrm{x}}\right)$ by reduction in the initial phase of catalyst operation. C-C coupling apparently takes place on the modified acidic centre of the zeolite. The $\mathrm{sp}^{2}$-coordinated carbon formed on the catalyst surface site for benzene formation (Xie, et al. 2004). A catalytic activity of some forms of carbon was also established by [14] investigating the methane aromatization over pyrolytic carbon.

As an alternative possibility, the mechanism of benzene formation via acetylene trimerization on transition metal catalysts was investigated by variety of spectroscopic and kinetic methods $[15,16]$. The authors agree upon acetylene trimerization via a surface $\mathrm{C}_{4}$ metallocycle, proposing the following path way for the formation of benzene: acetylene adsorbed on the surface converts into vinylidyne; this can react with gas phase acetylene to form $\mathrm{C}_{4} \mathrm{H}_{4}$ intermediate which was identified on the metal surfaces by an intermediate which was identified on the metal surfaces by NEXAFS [17-19]. The $\mathrm{C}_{4} \mathrm{H}_{4}$ compound reacts further with acetylene to produce benzene.

We consider that the difference of acid sites between $\mathrm{K}$ doped and undoped catalysts is the most important factor to influence the catalytic performance of two systems. We suggest that the $\mathrm{K}$ doped sample we suggest contains two types of pore channels: one is the two dimensional sinusoidal channels and the other the super-cage channels. The $\mathrm{K}$ undoped sample produces sinusoidal channels which acts as the reaction location of aromatization are smaller than the $\mathrm{K}$ doped sample which is perhaps the primary reasons that $\mathrm{K}$ doped catalyst can get higher selectivity for benzene and other hydrocarbons and less coke formation. This accord with the common theory considering carbon deposits causes deactivation and different behavior between two samples.

$\mathrm{CH}_{4}$ was converted into higher hydrocarbons and aromatics in relatively good yield on $\mathrm{K}$ doped sample. The catalytic performance and selectivity of $\mathrm{K}$ doped sample are strongly influenced by the extent of $\mathrm{K}: \mathrm{ZrO}_{\mathrm{x}}: \mathrm{MoO}_{\mathrm{x}}$ reduction. Nevertheless the behavior of $\mathrm{K}$ doped sample differs in many respects from undoped sample (Fig. 5). The main differences are as follows:

1. There is only a short induction period on $\mathrm{K}$ doped sampler: maximum $\mathrm{CH}_{4}$ conversion.

2. The coupling of acidic zeolite support and $\mathrm{K}$ shift the reaction towards the formation of increased aromatics and hydrocarbon selectivity through electron donation mechanism.

3. The $\mathrm{K}$ addition results in the increase in the progress of reduction of $\mathrm{Mo}^{+6}$. The temperature programmed reduction studies of the calcined catalyst with and with K presented in Fig. (5b) supports this argument.

The nature of active sites involved in the activation of methane leading to the production of ethylene as an intermediate remains an open question. These surface sites should satisfy the following basic requirements.
1. Activation of one of the $\mathrm{C}-\mathrm{H}$ bonds in the methane molecule to yield $\mathrm{CH}_{3}$.

2. Lower activity towards the decomposition of $\mathrm{CHx}$ fragments to carbon and

3. The selective production of lower hydrocarbon products.

The fact, that the main product of initial interaction of methane with $\mathrm{MoO}_{3}$ clearly shows that the active species is not $\mathrm{Mo}^{6+}$, but $\mathrm{KZrMo}^{4+}$. This also suggests that besides the $\mathrm{K}: \mathrm{Zr}: \mathrm{Mo}$ and $\mathrm{Zr}: \mathrm{Mo}$ active sites, the presence of some other oxygen deficient $\mathrm{MoO}_{2}$ is also necessary for the activation of methane and that oxygen deficient species comes from the $\mathrm{K}$ and acidified zeolite. The reaction of polarized molecule, $\mathrm{H}^{-}$ $-\mathrm{CH}_{3}{ }^{+}$, on the Bronsted acid sites of $\mathrm{K}$ doped catalyst sample results in the change in methane aromatization and \% conversion as presented in Fig. (5). On the basis of the arguments presented above, a mechanism of the reaction is proposed and presented in Fig. (6).

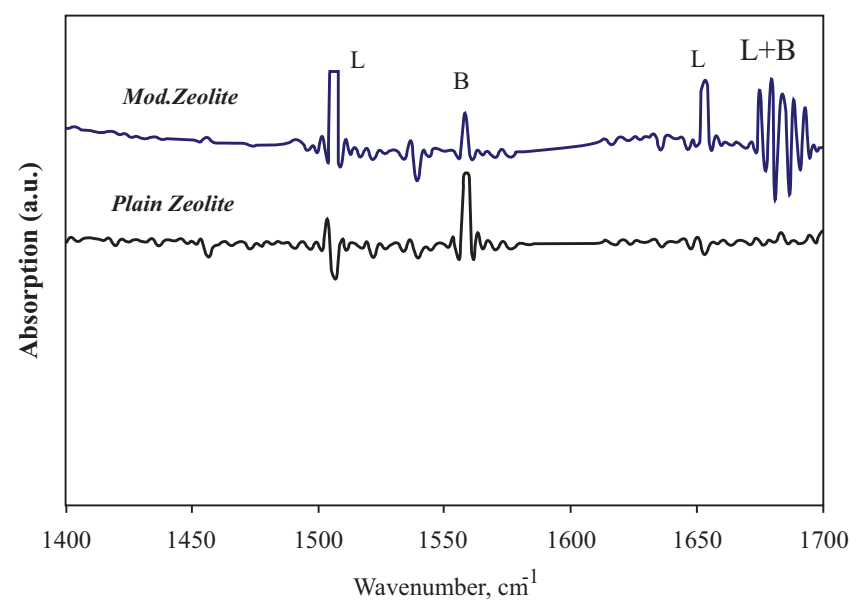

Fig. (5a). FTIR analysis of the modified Zeolite 5 .

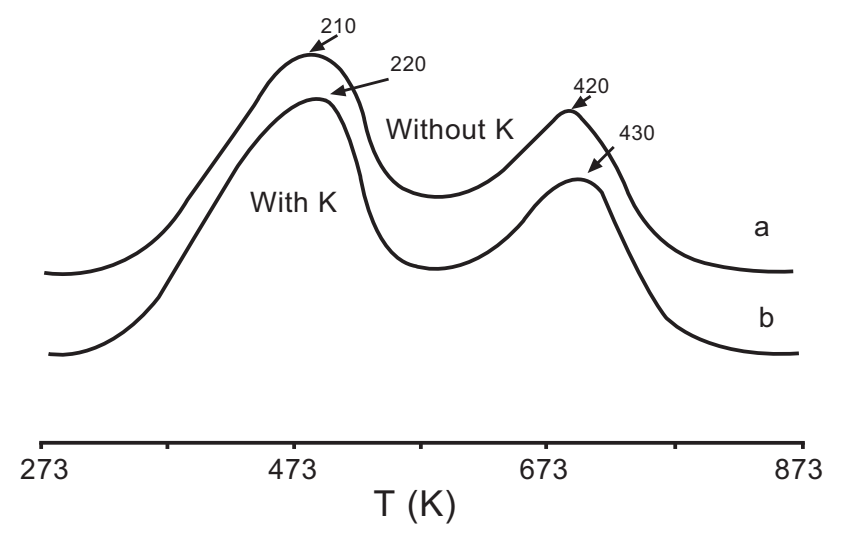

Fig. (5b). TPR studies of the $\mathrm{K}$ doped and undoped catalyst samples.

The driving force for the increase in Product selectivity on the $\mathrm{K}$ and zeolite modified can be related to electron band properties of bimetallic solids metals interaction with the support. For example, a possible mechanism described above could involve a continuous increase with time, the surface coverage of intermediate linked to aromatics and hydrocarbon species formation. This remains adsorbed due to electrostatic forces, up to coverage state where electrons 


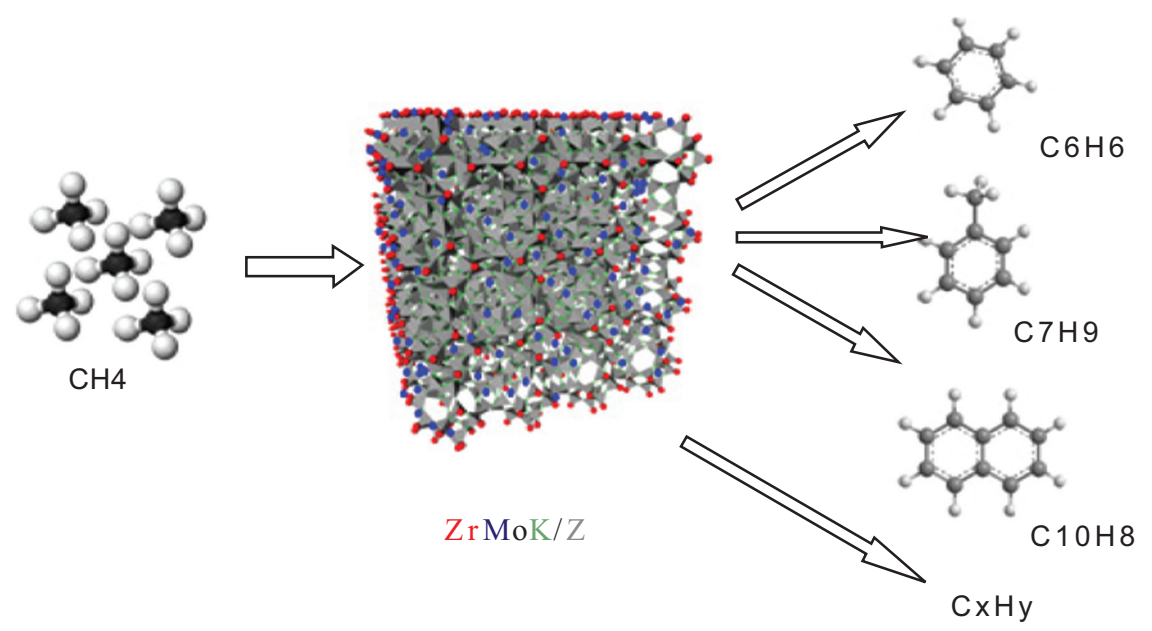

Fig. (6). The Possible mechanism of aromatics and hydrocarbon formations.

charging solid reach a critical value which activates electron return to surface to neutralize the intermediate and therefore, producing desorption. The increase in contact time with the availability of multiple catalytic active sites probably produces rich intermediate concentration leading to increase in the aromatics and hydrocarbon production. We also proposes here that intermediate formation concentration in which $\mathrm{K}$ and Bronsted acid sites of zeolites plays a vital role inhibits the coke formation. Accordingly, the ability of modified zeolite to impede irreversible adsorption of large amount of hydrocarbons formation leading to coke formation, hence, it keeps clear extension of active surface for continuous product production.

In a further attempt to relate activity to the morphological data of these catalysts, the maximum rates were plotted against surface area (Fig. 7). Here an increase in the rate is observed with increasing surface area.

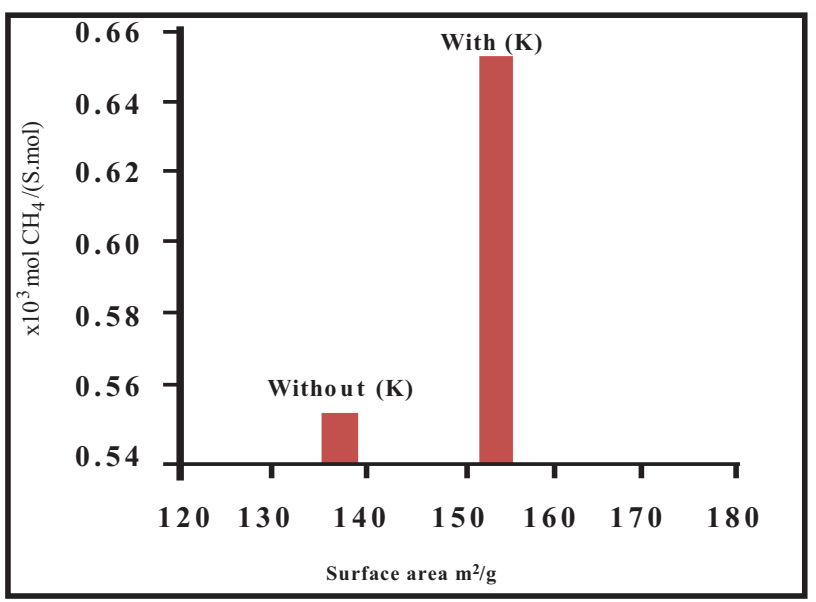

Fig. (7). Variation of rate of product formation $\left(r_{\max }\right.$ with surface area.

Finally, the rate could well be a function of both external site density and the available surface area, obeying the following relationship.

$\mathrm{R}=\mathrm{kn} \mathrm{S}_{\text {catal. }}$.

where $\mathrm{n}$ is the number of acid sites per unit cell in the BET surface area $\left(\mathrm{S}_{\text {catal })}\right)$.
The result of this attempt to relate the rate to both surface area and acid site density is shown in Fig. (8), where kn is plotted against $S_{\text {catal }}$. Studying Fig. (8) it could be suggested that the effect of potassium and increase in Bronsted acid sites played a vital role in the catalytic studies. Clearly most of the reaction proceeds on the surface area of the system where catalytic surface sites and its geometry plays an important role in defining the out put. This is not unexpected at these high space velocities and high temperatures. Transport phenomena very often determine the efficiency of the catalyst even in the case of small molecules as small as methane.

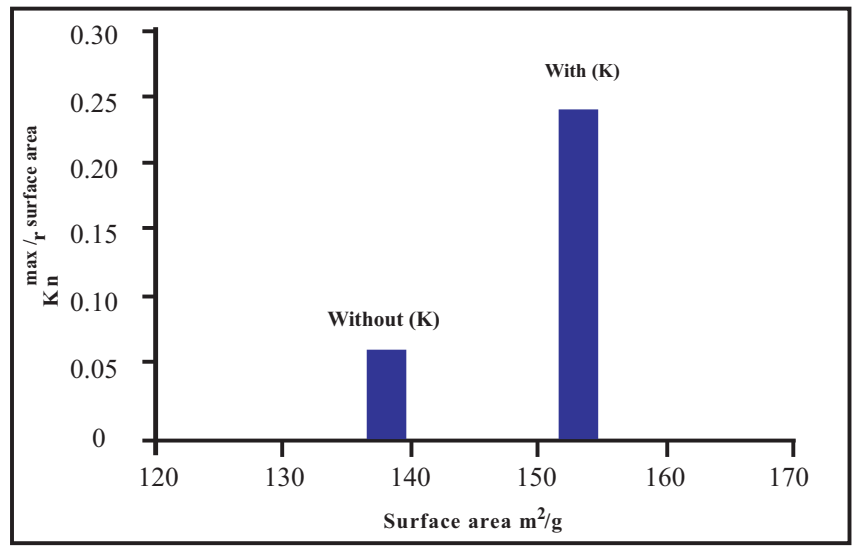

Fig. (8). Variation of the ratio of maximum rate of hydrocarbon formation to the no. of acid sites $\left(\mathrm{r}_{\max } / \mathrm{n}_{\text {surface area) }}\right.$ for Catalyst without $\mathrm{K}$ and with $\mathrm{K}$.

Further work is in progress to study the effect on natural gas conversion, carbon reduction, product selectivity and percentage yield with varying concentration of $\mathrm{Zr}$, Mo and $\mathrm{K}$.

\section{CONCLUSIONS}

1. The results presented and demonstrated the principal feasibility of converting methane into benzene and toluene by acidifying the zeolite $5 \mathrm{~A}$ creating highly enriched Bronsted acid sites.

2. The electronic surface modification by the addition of potassium which results in the increase in electron 
donating capability of the system, results not only in the reduction of carbon on the surface during catalytic studies, but also increases its stability.

\section{REFERENCES}

[1] Oró, J.; Han, J. High-temperature synthesis of aromatic hydrocarbons from methane. Science, 1966, 153, 1393-95.

[2] Abdelrehim, I.M.; Thornburg, N.A.; Sloan, J.T.; Caldwell, T.E.; Land, D.P. Kinetics and mechanism of benzene formation from acetylene on $\operatorname{pd}(111)$ studied by laser-induced thermal desorption/fourier transform mass spectrometry. J. Am. Chem. Soc., 1995, 117, 9509-14

[3] Barath, F.; Turki, M.; Keller, V.; Maire, G. Catalytic Activity of Reduced $\mathrm{MoO}_{3} / \alpha-\mathrm{Al}_{2} \mathrm{O}_{3}$ for Hexanes Reforming: I. preparation, characterization, and $\mathrm{x}$-ray photoelectron spectroscopy studies. $J$. Catal., 1999, 185, 1-11.

[4] Lucia, R.; Araujo, R.; Schmal, M. Pt-Cr/ZSM-5 catalysts for propane and cyclohexane conversions. Appl. Catal. A, 2002, 235, $139-47$.

[5] Claridge, J.B.; Green, M.L.H.; Tsang, S.C.; York, A.P.E. Oxidative oligomerisation of methane to aromatics. Appl. Catal. A, 1992, 89, 103-116.

[6] Heintze, M.; Magureanu, M. Methane conversion into aromatics in a direct plasma-catalytic process. J. Catal., 2002, 206, 91-97.

[7] Hussain, S.; Hajmrle, K. Hydrometallurgical process for the production of supported catalyst. 2004, US Patent No. 2004033894.

[8] Inui, T.; Ishihara, Y.; McKamachi, K.; Matsuda, H. Pt Loaded HIGH-Ga Silicates for Aromatization of Light Paraffins and Methane. Stud. Surf. Sci. Catal., 1989, 49, 1183-92.

[9] Logan, M. A.; Rucker, T. G.; Gentle, T. M.; Muetterties, E. L.; Somorjai, G. A. Conversion of acetylene to benzene over palladium single-crystal surfaces. II. The effect of additives. J. Phy. Chem. 1986, 90, 2709-15.
[10] Larachi, F.; Hassani, H.O.; Iliuta, M.C.; Grandjean, B.P.A.; McBreen, P.H. Ru-Mo/HZSM-5 catalyzed methane aromatization in membrane reactors. Catal. Lett., 2004, 84, 183-92.

[11] Murata, K.; Ushijima, H. Dehydrogenation-aromatisation of methane on amorphous-like carbons. J. Chem. Soc. Chem. Commun., 1994, 10, 1157-58.

[12] Naif, M.; Hutchings, G. Aromatization of isobutene using h-zsm5/oxide composite catalysts. Catal Lett., 2009, DOI: 10.1007/s10562-009-0255-x

[13] Óvári, L.; Solymosi, F. Determination of acidic centers on supported $\mathrm{Mo}_{2} \mathrm{C}$ catalysts. J. Mol. Catal. A. Chem., 2004, 207, 3540 .

[14] Sharifah, B.; Hamid, D.A.; Anderson, J.R.; Schmidt, I.; Bouchy, C.; Jacobsen C.J.H.; Derouane, E.G. Effect of the activation procedure on the performance of Mo/H-MFI catalysts for the nonoxidative conversion of methane to aromatics. Catal. Today, 2000, 63, 461-69.

[15] Sara, S.; Masiero, Nilson, R.; Lopez, O.W.P. Aromatization of methane over mo-fe/zsm-5 catalysts. Catal. Lett., 2009, 131, 194202.

[16] Vosmerikov, A.V.; Zaikovskii, V.I.; Korobitsyna, L.L.; Echevskii, G.V.; Kozlov, V.V.; Barbashin, Y.E.; Zhuravkov, S.P. Nonoxidative conversion of methane into aromatic hydrocarbons on Ni-Mo/ZSM-5 catalysts. Kinet. Catal., 2009, 50, 725-33.

[17] Wang, L.; Tao, L.; Xie, M.; Xu, G.; Huang, J.; Xu, Y. Dehydrogenation and aromatization of methane under nonoxidizing conditions. Catal. Lett., 1993, 21, 35-41.

[18] Xie, Y.; Wang, B.; Wang, L.; Bai, J. Resonance-enhanced 2-photon ionization studies of induction period of methane dehydroaromatization over Mo/HZSM-5. Reaction Kinetics. Catal Lett., 2004, 83, 99-103.

[19] Xu, C.; Guan, J.; Wu, S.; Jia, M.; Wu, T.; Kan, Q. Catalytic performance of zeolite ITQ-13 with 9- and 10-member rings for methane dehydroaromation. Reaction Kinetics, Mech. Catal. 2010, DOI: $10.1007 / \mathrm{s} 11144-009-0129-7$. 